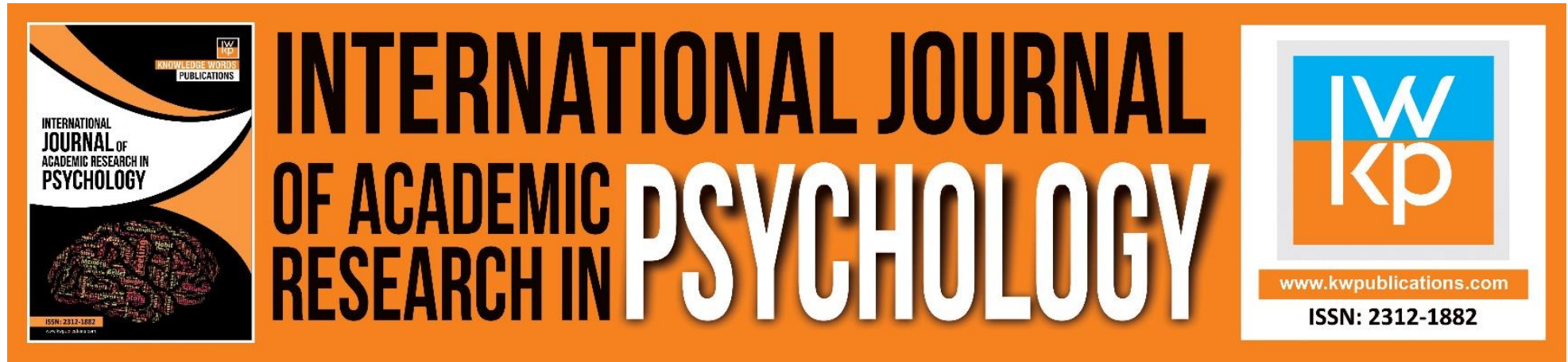

\title{
Differences of Mental Health among Orphan and Non-Orphan Adolescents
}

Sanurizwanie Mat Sahad, Zakaria Mohamad, Madihah Mohamad Shukri

To Link this Article: http://dx.doi.org/10.46886/IJARP/v4-i1/3492

DOI: $10.46886 /$ IJARP/v4-i1/3492

Received: 25 May 2017, Revised: 28 July 2017, Accepted: 18 August 2017

Published Online: 30 August 2017

In-Text Citation: (Sahad et al., 2017)

To Cite this Article: Sahad, S. M., Mohamad, Z., Shukri, M. M. (2017). Differences of Mental Health among Orphan and Non-Orphan Adolescents. International Journal of Academic Research in Psychology. 4(1), 20-29.

\section{Copyright: (C) 2017 The Author(s)}

Published by Knowledge Words Publications (www.kwpublications.com)

This article is published under the Creative Commons Attribution (CC BY 4.0) license. Anyone may reproduce, distribute, translate and create derivative works of this article (for both commercial and non-commercial purposes), subject to full attribution to the original publication and authors. The full terms of this license may be seen

at: http://creativecommons.org/licences/by/4.0/legalcode

\section{Vol. 4, No. 1, 2017, Pg. 20 - 29}

https://kwpublications.com/journals/journaldetail/IJARP

JOURNAL HOMEPAGE

Full Terms \& Conditions of access and use can be found at https://kwpublications.com/pages/detail/publication-ethics 


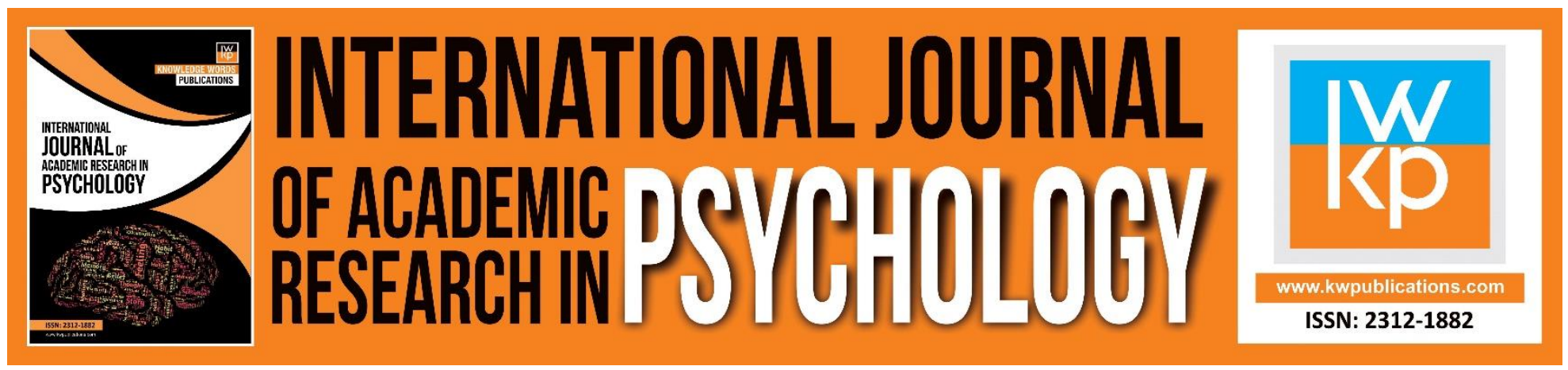

\title{
Differences of Mental Health among Orphan and Non- Orphan Adolescents
}

\section{Sanurizwanie Mat Sahad, Zakaria Mohamad, Madihah Mohamad Shukri}

Department of Psychology and Counseling, School of Social and Economic Development, University Malaysia Terengganu, 21300 Kuala Terengganu, Terengganu, Malaysia.

\begin{abstract}
The study aims to identify the differences of mental health among orphan and non-orphan adolescents in Malaysia. This study used a quantitative method. The sample comprised of 240 orphans and 240 non-orphan adolescents, aged 13 to 17 years old selected through multistage sampling. The validated Malay version of Depression, Anxiety, Stress Scale 21 Item (DASS21) used in this study to measure mental health among the orphan and non-orphan adolescents. The findings showed that there have differences of mental health among orphan and non-orphan adolescents which is orphans had significantly higher level of mental health problem than non-orphan respectively; depression, anxiety and stress. Result revealed that all parties including government organization, non-governmental organizations (NGOs), orphanage centers and guardians need to regulate actions such as program implementation and intervention to ensure the continuity of mental health especially among orphan adolescents in Malaysia.
\end{abstract}

Keywords: Mental Health, Depression, Anxiety, Stress, Orphan Adolescent, Non-Orphan Adolescent.

\section{Introduction}

Mental health is an important element for childhood and adolescents health development (Greydanus \& Merrick, 2012; Waddell et al., 2007). Adolescents who have good mental health are able to recognize their own abilities, can handle normal stresses in life and able to contribute to the community (World Health Organization, 2012). However, there are psychological issues that contributed to the mental health disorders among adolescents nationwide (Mohammadzadeh et al., 2017a; Chen et al., 2017; Aud, Ramani \& Frohlich, 2011; Suldo \& Shaffer, 2008).

Based on reports from the World Health Organization (WHO), mental health disorders in children and adolescents have increased each year and this issue will continue to increase by $50 \%$ until 2020 (Bayera et al., 2010). In 2015, the National Health and Morbidity Survey Statistics has been implemented by the Ministry of Health Malaysia $(\mathrm{MOH})$, found that adolescents are among those 
INTERNATIONAL JOURNAL OF ACADEMIC RESEARCH IN PSYCHOLOGY

Vol. 4, No. 1, 2017, E-ISSN: 2312-1882 @ 2017 KWP

with the highest number of people experiencing mental health, especially aged 16 to 19 years of which 29.2\% comprised 4.2 million people more than 31 million Malaysians (Ministry of Health, 2015).

However, mental health disorders are highest among orphan adolescents who living in orphanages. Previous studies showed that mental health disorders among orphans are higher than non-orphans adolescents (Mohammadzadeh et al., 2017a; Hashim et al., 2011; Kaur \& Rani, 2016; Bhat, Rahman, $\&$ Bhat, 2015). Studies have shown adolescents who living in orphanages are exposed to various emotional disorders such as depression, anxiety and stress (Mohammadzadeh et al., 2017a; Nurulwahida, Aizan \& Khaliza, 2014; Lehman et al., 2013). In Asia, there are 68.9 million orphans who shown the largest number in the world (Orphan Facts \& Statistics, 2005). Based on statistics from the United Nations (UN), over 400 thousand children in Malaysia have been orphaned since 2015 and this number is expected to increase every year (Lakshiny, 2015). However, there are no detailed statistics stating the exact number of orphanage in Malaysia because as many unregistered with formal organizations (Mohammadzadeh et al., 2017a).

According to the growing number of orphans, it seems that the orphanage are the primary choice for those who are unlucky to live with other relatives (Polihronakis, 2008; Nair, 2014). In Terengganu, orphan adolescents from all the district were centered at the Terengganu Orphan Welfare Organization (PERKAYA) which is this situation make a crowded number of orphan adolescents and gave a distress to guardians to control to all residents (PERKAYA, 2017). Orphans those living at the orphanages are seen to face that environment to continue their daily lives without enough attention from their guardians. Therefore, they are more likely to have various of emotional and behavioral problems such as depression, anxiety and stress which are totally different compared to non-orphan adolescents (PERKAYA, 2017).

Previous study showed that orphan adolescents suffered high emotional problem compared nonorphan adolescents at a school in Acera, Ghana (Yendork \& Somhlaba, 2015). According to Cluver and Gardner (2006), orphan adolecents in Cape Town, South Africa experiencing mental health disorders such as depression and anxiety. Studies have shown orphan adolescents brought up in orphanages are exposed to various of emotional and behavioral problems such as depression, anxiety, stress and anti-social behavior (Lehmann et al, 2013; McLaughlin, Zeanah, Fox, \& Nelson, 2012; Fawzy \& Fouad, 2010).

In 2017, a local study have found that orphans living in orphanage centers in Selangor suffer from depression, anxiety and stress (Mohammadzadeh et al., 2017a). Another study in 2014 showed that orphan adolescents in Malaysia exposed to Major Depression Disorder (MDD) (Wan Salwina et al., 2014) than non-orphan adolescents (Kaur et al., 2014; Wahab et al., 2013; Hashim et al., 2011). More than $50 \%$ of orphans have mild to severe depression in Kelantan (Ramli et al., 2010). Furthermore, according to Mohammadzadeh et al. (2017b) study also indicates that orphans have higher levels of stress compared to non-orphan adolescents (Yaacob et al., 2009; Sulaiman et. al., 2009).

However, only a few local studies have examined the psychological well-being or conducted educational interventions among adolescents who living in orphanages (Mohammadzadeh et al, 
2017b; Syazrah et al., 2015; Nurulwahida, Aizan \& Khaliza, 2014; Wan Salwina et al., 2014; Ramli, Yahaya \& Lazin, 2010; Roslee et al., 2004). In addition, local reseachers have not yet give the proper attention on studies among between group of adolescents; orphan and non-orphan. Local studies have focused on mental health among different samples such as school students (Norhayati, 2013; Hashim et al., 2011) and IPT students (Shamzaeffa \& Tan, 2016; Shamsuddin, et al., 2013; Nurhaila, et al., 2011). Therefore, information about mental health among orphan adolescents is very limited and the lack of information in this area become the major challenge to develop effective intervention and treatment programs among orphan adolescents in Malaysia. Hence, this current study is an effort to contribute information on mental health among orphan adolescents, which by identifying the different levels of mental health among orphan and non-orphan adolescents.

\section{Methodology}

\section{Sample and Procedure}

A total of 240 adolescents from one orphanage center and 240 non-orphan adolescents in a school in Terengganu, Malaysia, aged 13 to 17 year olds are involved in this descriptive study. The samples were selected using multi stage sampling. The orphan adolescents who has lost biological father and both parents were involved in this current study (the condition in the orphanage). Meanwhile, for those still have both parents and live together in category as non-orphan adolescents.

\section{Research Instrument}

Data collection was carried out by administered validated Malay version of Depression, Anxiety, Stress Scale 21 Item (DASS21) to measure mental health among samples.

\section{Depression, Anxiety, Stress Scale 21 Item (DASS21)}

Depression, Anxiety, Stress Scale version 21 Item (DASS21) is a modified questionnaire from the DASS version of the 42 questionnaire developed by Lovibond and Lovibond (1995). The translated DASS21 questionnaire has been used in this study to measure the level of depression, anxiety and stress with reliability (depression, 0.8; anxiety, 0.74 and stress 0.79) (Ramli et al, 2007). The answer format for this questionnaire consists of four likert scale to describe the samples' condition throughout the week before answering the questionnaires from (0) Never, (1) Sometimes, (2) Often and (3) Almost Always.

\section{Data Analysis}

In this study, the quantitative data obtained was processed and analyzed using the Statistical Package for Social Sciences (SPSS) for WINDOW version 23.0. Methods of inferential statistical analysis of Independent Sample t-Test were used to determine the differences of mental health (depression, anxiety and stress) among the samples.

\section{Findings}

Based on the DASS21 questionnaire, the mental health level is measured based on the elements of depression, anxiety and stress. The findings show that there was a significant difference in the score of depression between orphan and non-orphan adolescents; $t(478)=6.27, p<.001$. Thus, the results of the study showed that the level of depression of orphans was higher $(m=2.38, \mathrm{Sd}=0.85)$ compared with non-orphan adolescents $(\mathrm{m}=1.89, \mathrm{Sd}=0.85)$. In addition, the results also showed that there was 
INTERNATIONAL JOURNAL OF ACADEMIC RESEARCH IN PSYCHOLOGY

Vol. 4, No. 1, 2017, E-ISSN: 2312-1882 @ 2017 KWP

a significant difference in the score of anxiety between orphan and non-orphan adolescents; $t$ (478) $=5.03, p<.001$. The results showed that the level of anxiety among orphans was higher $(m=3.44$, $\mathrm{Sd}=1.31)$ compared to non-orphan adolescents $(\mathrm{m}=2.82, \mathrm{Sd}=1.37)$. Moreover, there was also significant difference in the score of stress between orphan and non-orphan adolescents; $\mathrm{t}(478)=$ $2.15, p<.05$. The results showed that the level of the stress among orphans was higher $(m=1.73$, $\mathrm{Sd}=0.89)$ compared to non-orphan adolescents $(\mathrm{m}=1.57, \mathrm{Sd}=0.75)$. The overall findings are shown in Table 1.

Table 1.0 Differences of mental health among orphan and non-orphan adolescents

\begin{tabular}{lcccccc}
\hline & \multicolumn{2}{c}{$\begin{array}{c}\text { Orphan } \\
\text { Adolescents }\end{array}$} & \multicolumn{2}{c}{$\begin{array}{c}\text { Non-orphan } \\
\text { adolescents }\end{array}$} \\
\cline { 2 - 7 } Variable & Mean & Sd & Mean & Sd & t & Sig \\
\hline Depression & 2.38 & 0.85 & 1.89 & 0.85 & 6.267 & 0.00 \\
Anxiety & 3.44 & 1.31 & 2.82 & 1.37 & 5.031 & 0.00 \\
Stress & 1.74 & 0.89 & 1.57 & 0.75 & 2.152 & 0.03 \\
& & & & & & \\
\hline
\end{tabular}

\section{Discussion and Conclusion}

Mental health disorders such as depression, anxiety and stress among adolescent and early adult worldwide is currently estimated to range from 5 to $80 \%$ in different populations (Sahoo \& Khess, 2010). Depression, anxiety and stress also are among major psychiatric conditions being prevalent in contemporary youth (Buzdar et al., 2015). However, previous studies have shown that adolescents living in orphanage centers suffer from mental health problems rather than non-orphan adolescents (Mohammadzadeh et al., 2017a; Hashim et al., 2011; Kaur \& Rani, 2016; Bhat, Rahman, \& Bhat, 2015).

The result of the current study, reported that orphans have emotional problems such as depression, anxiety and stress higher than non-orphan adolescents. This explained that orphan adolescents was experienced lower mental health. The results of previous studies in Malaysia also showed that orphans living in orphanage centers are more depressed (Mohammadzadeh et al., 2017a) and exposed to Major Depression Disorder (MDD) (Wan Salwina et al., 2014) compared to non-orphan adolescents (Hashim et al., 2011; Kaur et al., 2014). In addition, more than $50 \%$ of orphan adolescents have mild to severe depression (Ramli et al., 2010). The result of the current study have also shown consistent findings with previous studies which is orphans have experienced higher levels of anxiety and stress than non-orphan adolescents (Mohammadzadeh et al., 2017a; Wahab et al., 2013; Yaacob et al., 2009; Sulaiman, Hassan, Sapian, Vizata, \& Saifuddin, 2009).

Besides, oversea studies revealed that orphans adolescents have experienced high depression (Kaur \& Rani, 2016; Workye, 2015; Bhat et al., 2015; Bhat, 2014) and exposed to behavioral problems such as aggressive and anti-social behavior (Lehmann et al, 2013; Simsek et al., 2007) compared to adolescents who still have both parents (Akshita Singh \& Suvidha, 2016; Irshad, 2015; Kumar et al., 
2014; Wild et al., 2006). The difference of negative events experienced by orphan adolescents has caused them suffering mental health disorders such as depression, anxiety and stress (Elegbeleye, 2014; Sujatha \& Jacob, 2014; Fawzy \& Fouad, 2010; Thabet et al., 2007) compared to non-orphan adolescents (Dorsey et al., 2015; Afework, 2013; Nyamukapa et al., 2010; Kaggwa \& Hindin, 2010; Olley, 2008).

The negative event such as lost of parents at an early age, has caused orphan adolescents lost of parental attachment in their lives. Living in orphanages, deprived orphan adolescents from their parents attention and loves. They faced the different environment before the death of their parents (Irudayasamy, 2006). Negative outcomes are very common among orphan adolescents due to poor care-giving from guardian at orphanages (Thabet et al., 2007). These situation influenced orphan adolescents to experience emotional disorders such as depression, anxiety and stress (Deutsch et al., 2015; Dorsey et al., 2015; Afework, 2013) compared with non-orphans adolescents who still have the opportunity to get attention, love and affection from their parents (Hashim et al., 2011; Harms et al., 2009).

In conclusion, the purpose of this study was to identify the difference in mental health among orphan and non-orphans in Terengganu, Malaysia. The findings of this study were in agreement with the majority of previous studies that confirmed the differences of mental health among orphan and nonorphans adolescents. The information obtained from this current study provide benefits and implications to various parties such as the State Social Welfare Department (JKM), non-governmental organizations (NGOs), parties in the orphanage care centers, teachers and other parties involved in the management of orphanages especially in Terengganu, Malaysia.

Unfortunately, there is not much reliable data and information of mental health among orphan adolescents from various categories such as "maternal orphan" (a child who has lost her/his mother), "paternal orphan" (a child who has lost her/his father), and lost both parents living in orphanage in Malaysia. Since this current study only examines orphan adolescents from "paternal orphan" (a child who has lost her/his father) and lost both parents categories, this situation makes it a major limitation to be taken by future researchers to ensure the continuity of mental health among orphan adolescents, especially in Malaysia. Further studies with different orphans in all orphanage centers in Malaysia, different ages and races as well as to use different tools are suggested to reach a reliable image of mental health among orphan adolescents Malaysia with more thoroughly and comprehensively.

\section{Acknowledgement}

I am very thankful to Associate Prof. Dr Zakaria and Dr. Madihah for supervising me throughout the research. Thank also to my families and friends who have supported me all these year.

\section{Corresponding Author}

Sanurizwanie Mat Sahad

Department of Psychology and Counseling, School of Social and Economic Development, University Malaysia Terengganu, 21300 Kuala Terengganu, Terengganu, Malaysia 
INTERNATIONAL JOURNAL OF ACADEMIC RESEARCH IN PSYCHOLOGY

Vol. 4, No. 1, 2017, E-ISSN: 2312-1882 @ 2017 KWP

Email: nurizwaniey1002@gmail.com

\section{References}

Afework, T. (2013). A Comparative Study of Psychological Well-being Between Orphan and Non orphan Children in Addis Ababa: The Case of Three Selected Schools in Yeka Sub City. Addis Ababa University: Addis Ababa.

Atwine, B., Cantor-Graae, E., \& Bajunirwe, F. (2005). Psychological distress among AIDS orphans in rural Uganda. Social Science \& Medicine, 61(3), 555-564.

Aud, S., Ramani, K. A., Frohlich, L. (2011). America's youth: transitions to adulthood (NCES 2012-026). US Department of Education. National Center for Education Statistics. US Government Printing Office, Washington, DC.

Azid, N., \& Yaacob, A. (2016). Enriching orphans' potentials through interpersonal and intrapersonal intelligence enrichment activities. International Journal of Instruction, 9(1), 17-32.

Bayera, A., Gilmanb, R., Tsuid, A., \& Hindind, M. (2010). What is adolescence? Adolescents narrate their lives in Lima, Peru. J. Adolescents. 33 (4), 509-520, http://dx.doi.org/10.1016/j.adolescence.2010.02.002.

Bhat, A. A., Rahman, S., \& Bhat, N. M. (2015). Mental Health Issues in Institutionalized Adolescent Orphans. International Journal of Indian Psychology, 3(1), 57-77.

Bhat, N. M. (2014). A study of emotional stability and depression in orphan secondary school students. International Journal of Education and Psychological Research (IJEPR). Retrieved from http://ijepr. org/doc/V3Is2_June14/ij20.pdf

Buzdar, M. A., Ali, A., Nadeem, M., \& Nadeem, M. (2015). Relationship between religiosity and psychological symptoms in female university students. Journal of Religion and Health, 54(6), 2155-2163.

Chen, W., Zhang, D., Pan, Y., Hu, T., Liu, G., \& Luo, S. (2017). Perceived social support an self esteem as mediators of the relationship between parental attachment and life satisfaction among Chinese adolescents. Personality and Individual Differences, 108, 98-102.

Cluver, L., \& Gardner, F. (2006). The Psychological Well-being of Children Orphaned by AIDs in Cape Town, South Africa. Ann Gen Psychiatry, 5(8). doi:10.1186/1744859x 5-8.

Cohen, S., Janicki-Deverts, D., \& Miller, G. E. (2007). Psychological stress and disease. Jama, 298(14), 1685-1687.

Deutsch, S. A., Lynch, A., Zlotnik, S., Matone, M., Kreider, A., \& Noonan, K. (2015). Mental health, behavioral and developmental issues for youth in foster care. Current Problems in Pediatric and Adolescent Health Care, 45(10), 292297.

Dorsey, S., Lucid, L., Murray, L., Bolton, P., Itemba, D., Manongi, R., \& Whetten, K. (2015). A qualitative study of mental health problems among orphaned children and adolescents in Tanzania. The Journal of Nervous and Mental Disease, 203(11), 864870.

Elegbeleye, A. O. (2014). Psycho-social predictors of mental health among orphans in Southwest Nigeria: Efficacy of psycho-education intervention (Doctoral dissertation). Covenant University.

Ghazalli, F. S. M., Nurdin, M. F., \& Abdul Ghani, N. (2015). Acceptance of orphan emotional service at shelter house: Study at Islamic Women's Orphanage, Penang. International Conferences on Empowering Islamic Civilazation in the 21th Century. Universiti Sultan Zainal Abidin. 
Fawzy, N., \& Fouad, A. (2010). Psychosocial and developmental status of orphanage children: Epidemiological study. Current psychiatry, 17(2), 41-48.

Fink, G. (2010). Stress: definition and history. Stress science: neuroendocrinology, 39.

Greydanus, D. E., \& Merrick, J. (2012). Adolescent mental health. International Journal of Child Health and Human Development, 5(2), 143-148.

Harms, S., Kizza, R., Sebunnya, J., \& Jack, S. (2009). Conceptions of mental health among Ugandan youth orphaned by AIDS. African Journal of AIDS Research, 8(1), 716.

Hashim, H. A., Golok, F., \& Ali, R. (2011). Factorial validity and internal consistency Malaysian adapted Depression Anxiety Stress Scale-21 in an adolescent sample. Journal of Collaborative Research on Internal Medicine \& Public Health, 3(1), 2939.

Irshad, S. (2017). A comparative study stress and alienation among orphans and normal. The International Journal of Indian Psychology, 2(93), 2349-3429.

Irudayasamy, P. (2006). Institute of research and development and rural poor. In Naqshbandi, M. M., Sehgal, R., \& Hassan, F. (2012). Orphans in orphanages of Kashmir "and their psychological problems." International NGO Journal, 7(3), pp.5563.doi:10.5897/INGOJ12.016

Kaggwa, E. B., \& Hindin, M. J. (2010). The psychological effect of orphan-hood in a matured HIV epidemic: An analysis of young people in Mukono, Uganda. Social Science \& Medicine, 70(7), pp.1002-1010.

Kaur, S., \& Rani, C. (2016). Exploring psychological health of orphan adolescents: A comparative analysis. International Journal of English Language, Literature and Humanities, 4(6).

Ministry of Health. (2015). A healthy lifestyle campaign: Mental health. Kuala Lumpur: Health Education Division Ministry of Health Malaysia.

Kumar, S. P., Dandona, R., Kumar, G. A., Ramgopal, S. P., \& Dandona, L. (2014). Depression among AIDS-orphaned children higher than among other orphaned children in southern India. International Journal of Mental Health Systems, 8(1), 13.

Lakshiny, P. (2015). Adoption is always an option, but are you ready to commit to it? Retrieved from http://www.malaysiandigest.com/opinion/569313-adoption is always an-option-but-areyou-ready-to-commit to-it.html.

Lawrence, D., Johnson, S., Hafekost, J., Sawyer, M., \& Ainley, J. (2015). The mental health of children and adolescents: Report on the second Australian child and adolescent survey of mental health and wellbeing. Australia: Department of Health.

Lehmann, S., Havik, O. E., Havik, T., \& Heiervang, E. R. (2013). Mental disorders in fosterchildren: A study of prevalence, comorbidity and risk factors. Child and Adolescent Psychiatry and Mental Health, 7(1), 39.

Lovibond, P. F., \& Lovibond, S. H (1995). The structure of negetive emotional states: Comparison of the Depression Anxiety Stress Scales (DASS) with the Beck Depressions and Anxiety inventories. Behaviour Research and Therapy 33, 335343

MacLeod, C. (1999). Anxiety and anxiety disorders. Handbook of cognition and emotion, 447.

McLaughlin, K. A., Zeanah, C. H., Fox, N. A., \& Nelson, C. A. (2012). Attachment security as a mechanism linking foster care placement to improved mental health outcomes in previously institutionalized children. Journal of Child Psychology and Psychiatry, 53(1), 46-55. 
Mohammadzadeh, M., Awang, H., Shahar, H. K., \& Ismail, S. (2017a). Emotional health and self esteem among adolescents in Malaysian orphanages. Community Mental Health Journal, 1-9. Doi: 10.1007/s10597-017-0128-5

Mohammadzadeh, M., Awang, H., Hayati, K. S., \& Ismail, S. (2017b). The effects of a life skills based intervention on emotional health, self-esteem and coping mechanisms in Malaysian institutionalised adolescents: Protocol of a multicentre randomized controlled trial. International Journal of Educational Research, 83, 32-42.

Nair, S. (2014). Of the 8 million kids in institutions worldwide, more than $90 \%$ aren't orphans. Retrieved November 4, 2017, from http://www.thestar.com.my/Lifestyle/Family/Features/2014/07/25/Of-the 8million-kids-ininstitutions-worldwide-more-than-90percent-arent orphans/.

Normaswati, T. (2003). Depression in Malay's out-patient: A survey at the Sultanah Aminah Hospital, Johor Bahru's psychiatric clinic. Bachelor Projects. Johor Bahru: UTM

Nyamukapa, C. A., Gregson, S., Wambe, M., Mushore, P., Lopman, B., \& Mupambireyi, Z. (2010). Causes and consequences of psychological distress among orphans in Eastern Zimbabwe. AIDS Care, 22, 96-98

Olley, B. O. (2008). Health and behavioural problems of children orphaned by Aids as reported by their caregivers in Abuja, Nigeria. Nigerian Journal of Psychiatry, 6(2), pp.7075. Abstract retrieved from http://ajol.info/index.php/njpsyc/article/view/39915

Orphan Statistics, Facts and Figures. (2012). Retrieved November 4, 2017, from http://www.sosusa.org/aboutsos/what/do/orphanstatistics/pages/default.spx.

Orphan Facts \& Statistics. (2005). Retrieved June 5, 2017, from Orphan Hope International http://www.orphanhopeintl.org/facts-statistics/.

PERKAYA. (2017). Terengganu Orphan Welfare Organization. Terengganu.

Polihronakis, T. (2008). Mental health care issues of children and youth in fostercare. United State: U.S. Department of Health and Human Services.

Ramli, M., Ariff, M. F., \& Zaini, Z. (2007). Translation, validation and psychometricproperties of Bahasa Malaysia version of the Depression Anxiety and Stress Scales (DASS). ASEAN Journal of Psychiatry, 8(2), 8289.

Ramli, J., Yahaya, A., Yahaya, N., \& Lazin, S. Z. (2010). Depression among the orphans in Kota Bharu, Kelantan. Journal of Science \& Mathematics Education. (Unpublished)

Sahoo, S., \& Khess, C. R. (2010). Prevalence of depression, anxiety, and stress among young male adults in India: A dimensional and categorical diagnoses-based study. The Journalof Nervous and Mental Disease, 198(12), 901-904.

Shamsuddin, K., Fadzil, F., Ismail, W. S. W., Shah, S. A., Omar, K., \& Muhammad, N. $\quad$ A. $\quad$ (2013). Correlates of depression, anxiety and stress among Malaysian university students. Asian Journal of Psychiatry, 6(4), 318-323.

Shri, R. (2010). Anxiety: causes and management. International Journal of Behavioral Science (IJBS), 5(1)

Simsek, Z., Erol, N., Öztop, D., \& Münir, K. (2007). Prevalence and predictors of emotional and behavioral problems reported by teachers among institutionally reared children and adolescents in Turkish orphanages compared with community controls. Children and Youth Services Review, 29(7), 883-899. 
Singh, A., \& Suvidha. (2016). Well Being of Orphan: A Review on Their Mental Health Status. Science and Technology, 2 (5), 2395-6011

Rozaina, S. K. (2014). Religious identity, self-concept, and resilience among female orphan adolescents in Malaysia: An evidence-based group intervention. Southern Illinois University at Carbondale

Sujatha, R., \& Jacob, S. M. (2014). Study on emotional and behavioural problems among adolescent children in selected orphanages at Mangalore. Zenith International Journal of Multidisciplinary research, 4(7), 253-259. Retreived from zenithresearch.org.in

Sulaiman, T., Hassan, A., Sapian, M., Vizata, A., \& Saifuddin, K. (2009). The level of stress among students in urban and rural secondary schools in Malaysia. European Journal of Social Sciences, 10(2), 179-184.

Suldo, S. M., \& Shaffer, E. J. (2008). Looking beyond psychopathology: The dual factor model of mental health in youth. School Psychology Review, 37(1), 52.

Swaran, L., \& Shikha, V. (2013). Mental health of HIV /AIDS orphans: A review. Journal of AIDS and HIV Research, Vol 5(12), pp.455-467. DOI:10.5897/JAH R2013.0271

Thabet, L., \& Thabet, A. A. M., Abdul, S., \& Vostanis, P. (2007). Mental health problems among orphanage children in the Gaza Strip. Adoption \& Fostering, 31(2), 54-62.

Waddell, C., McEwan, K., Peters, R. D., Hua, J. M., \& Garland, O. (2007). Preventing mental disorders in children: A public health priority. Canadian Journal of Public Health, 98(3), 174-178.

Wahab, S., Rahman, F. N. A., Hasan, W., Hafiz, W. M., Zamani, I. Z., \& Arbaiei, N. C. (2013). Stressors in secondary boarding school students: Association with stress, anxiety and depressive symptoms. Asia-Pacific Psychiatry, 5(S1), 8289.

Wan Salwina, W. I., Arunakiri, M., Cheah, Y. C., Ng, C. G., Shariff, R. M. R., \& Aili, H. H. (2014). Prevalence of depression in adolescents living in residential homes in Perak, Malaysia and its association with socio demographic and personal factors. Malaysian Journal of Psychiatry, 23(2), 4051.

Wild, L., Flisher, A., Laas, S., \& Robertson, B. (2006). Psychosocial adjustment of adolescents orphaned in the context of HIV/AIDS. Poster presented at the International Society for the Study of Behavioural Development Biennial Meeting, Melbourne, Australia.

World Health Organization [WHO]. (2012). Mental health: Strengthening our response. World Health Organization. Retrieved from http://www.who.int/mediacentre/factsheets/fs220/en/

Workye, T. (2015). Psychological wellbeing between institutional and non institutional orphan children in Gulele sub city, Addis Ababa. (Doctoral Thesis, Addis Ababa University, 2015).

Yaacob, S. N., Juhari, R., Talib, M. A., \& Uba, I. (2009). Loneliness, stress, self-esteem and depression among Malaysian adolescents. Jurnal Kemanusiaan, 14, 85-95.

Yaacob, S. N., Tan, S. A., Tan, J. P., \& Juhari, R. (2012). Malaysian adolescents' life satisfaction. Archives Des Sciences, 65(8).

Yendork, J. S., \& Somhlaba, N. Z. (2015). Problems, coping and efficacy: An exploration of subjective distress in orphans placed in Ghanian orphanages. Journal of Loss and Trauma. doi:10.1080/15325024.2014.949160. 